\title{
Passive smoking, salivary cotinine concentrations, and middle ear effusion in 7 year old children
}

\author{
D P Strachan, M J Jarvis, C Feyerabend
}

\begin{abstract}
Objective-To assess the contribution of passive exposure to tobacco smoke to the development of middle ear underpressure and effusion.

Design-Cross sectional observational study.

Setting-One third of the primary schools in Edinburgh.

Subjects -892 Children aged $6^{1 / 2}$ to $7^{1 / 2}$ were examined, and satisfactory tympanograms were obtained in 872. Results of assay of salivary cotinine concentrations were available for $\mathbf{7 7 0}$ children, and satisfactory tympanograms were available for $\mathbf{7 3 6}$ of these.
\end{abstract}

End point-Correlation of the prevalence of middle ear underpressure and effusion with concentrations of the marker of nicotine, cotinine, in the saliva of the children.

Measurements and main results-Middle ear pressure and compliance were measured in both ears by impedance tympanometry. Salivary cotinine concentrations were assayed by gas-liquid chromatography. Cotinine concentrations increased with the number of smokers in the household. Girls had higher concentrations than boys, and children living in rented housing had higher concentrations than those living in housing owned by their parents. There was a trend towards more abnormal tympanometric findings with increasing cotinine concentration, the odds ratio for a doubling of the cotinine concentration being $1 \cdot 14$ (95\% confidence interval 1.03 to 1.27). After adjustment for the sex of the child and housing tenure the odds ratio for a doubling of the cotinine concentration was $1.13(1.00$ to 1.28$)$.

Conclusions - The results of this study are consistent with those of case-control studies of children attending for an operation to relieve middle ear effusion. They indicate that the disease should be added to the list of recognised hazards associated with passive smoking. About one third of the cases of middle ear effusion in this study were statistically attributable to exposure to tobacco smoke.

\section{Introduction}

Middle ear effusion (glue ear) is the commonest reason for admitting young children for an operation, but little is known about its cause. ${ }^{2}$ Case-control studies of children admitted for insertion of a grommet have shown an increased risk associated with the presence of smokers in the household, ${ }^{3.5}$ particularly in children who had been exposed to high levels of tobacco smoke. ${ }^{3}$ Criteria for referral and admission for middle ear effusion seem to be determined substantially by the "health culture" of the family 6 and by local clinical practice, which may in turn be affected by the availability of services. ${ }^{7}$ Thus the interpretation of studies based on patients in hospital is complicated by selection bias, which may result in either a spurious relation with parental smoking or an underestimate of a true effect.

Five studies of children in the general population have reported on the association between middle ear effusion and passive exposure to smoke..$^{8-12}$ Only
Iversen et al found a significant association, and their results suggested that the risk associated with passive smoking increased with age. ${ }^{8}$ If this is so it might explain the negative results of the other studies, which were based on children aged less than 5 years old. ${ }^{9 \cdot 12}$

Both middle ear effusion and exposure to tobacco smoke can be measured objectively. Since its introduction some 20 years ago $^{13}$ impedance tympanometry has been widely used as a diagnostic and screening tool in young children, and its relation to fluid in the middle ear has been validated in patients attending for myringotomy. ${ }^{14}{ }^{15}$ Cotinine, an important metabolite of nicotine, is the most suitable marker to measure passive exposure to tobacco smoke. It is specific, has a half life of about 20 hours, and can be assayed in concentrations as low as $0.57 \mathrm{nmol} / 1(0.1 \mathrm{ng} / \mathrm{ml})$ by gas-liquid chromatography. ${ }^{16}$ Salivary concentrations of cotinine are roughly in proportion to those in blood and have been used to measure exposure to environmental tobacco smoke in adults ${ }^{1718}$ and adolescents. ${ }^{19} 20$

We investigated the relation between exposure to smoke and middle ear disease in a sample population of 7 year old schoolchildren who were participating in a survey of the effects of the home environment on respiratory health. ${ }^{21}$

\section{Subjects and methods}

A sample of one in three primary schools in Edinburgh was chosen at random, and the parents of all children in the third primary class (aged 61/2-71/2 years in September 1986) were contacted by postal questionnaire. This asked about respiratory symptoms and housing conditions relating to the child; more details are reported elsewhere. ${ }^{21}$ The current or latest occupation of the head of the household was coded to a social class according to the registrar general's classification of occupations. ${ }^{22}$ Written parental consent to clinical tests was requested, and ethical approval for the study was obtained from Lothian Health Board and Lothian Regional Council's education department.

Clinical tests were performed at the schools during January to June under the supervision of DPS. Middle ear pressure and compliance, the volume of the ear canal, and the relative gradient of the tympanometric curve were measured in both ears with a Microlab Earscan configured for impedance measurements (Micro Audiometrics, Florida, United States). This uses a probe tone of $226 \mathrm{~Hz}$ at $85 \mathrm{db}$ and sweeps from 200 to $-312 \mathrm{daPa}$ at $100 \mathrm{daPa} / \mathrm{s}$. The children were asked to swallow a sip of water immediately before the measurement was made to ensure that patent eustachian tubes would be ventilated. Table I shows the types of tympanograms, defined on the basis of the modification of Jerger's original classification ${ }^{23}$ that was proposed

TABLE I - Types of tympanograms according to Fiellau-Nikolajsen ${ }^{\prime 5}$

\begin{tabular}{lccl}
\hline Type & $\begin{array}{c}\text { Middle ear } \\
\text { pressure }(\text { daPa })\end{array}$ & $\begin{array}{c}\text { Gradient } \\
(\%)\end{array}$ & \multicolumn{1}{c}{ Interpretation } \\
\hline A & 200 to $-99 \cdot 9$ & $>10$ & Normal \\
C1 & -100 to $-199 \cdot 9$ & $>10$ & Mild underpressure \\
C2 & -200 to -312 & $>10$ & Severe underpressure \\
B & No peak & $<10$ & Middle ear effusion \\
\hline
\end{tabular}

London School of Hygiene and Tropical Medicine, London WC1E 7HT. 
and validated by Fiellau-Nikolajsen. ${ }^{15}$ To characterise each child the tympanogram obtained on examination of the more abnormal ear was used in the analysis.

The children were asked to collect saliva in their mouths and to spit into a clean plastic container. A sample of at least $1 \mathrm{ml}$ was frozen within eight hours after collection for assay of cotinine concentration by gas-liquid chromatography. ${ }^{16}$ Statistical analyses were performed by the statistical analysis system (SAS), ${ }^{24}$ and logistic regression models were fitted by the generalised linear interactive modelling system (GLIM) ${ }^{26}$ Tests for trend with one degree of freedom used the procedure proposed by Mantel $^{27}$ and implemented for stratified tabulations in the FREQ procedure in SAS. ${ }^{25}$

\section{Results}

The parents of 1095 children were sent a questionnaire, and $941(86 \%)$ consented to their child being examined clinically. Twenty of these children left school before the survey was carried out, and a further 20 were included in pilot studies. Of the remaining 901 eligible children, 892 (99\%) were examined, and satisfactory tympanograms were obtained for one or both ears in 872 . In 23 children results were obtained for only one ear, but these were included in the analysis.

Table II shows the relation between findings on tympanometry and the sex of the child, social class, housing tenure, and number of smokers in the household. There was no significant difference in middle ear pressure with sex or social class (when this was known), but the prevalence of middle ear effusion (type B tympanogram) was higher in girls and among

TABLE II-Prevalence (\%) of types of abnormalities on tympanometry of the more abnormal ear in 872 children aged 7 according to sex of child, socioeconomic state, housing tenure, and number of smokers in household. Numbers of children are given in parentheses

\begin{tabular}{|c|c|c|c|c|c|}
\hline & \multicolumn{5}{|c|}{ Middle ear pressure $(\mathrm{daPa})$} \\
\hline & $\begin{array}{c}100 \text { to }-100 \\
\text { (type A) }\end{array}$ & $\begin{array}{c}-200 \text { to }-100 \\
\text { (type } \mathrm{Cl})\end{array}$ & $\begin{array}{c}-300 \text { to }-200 \\
\text { (type C2) }\end{array}$ & $\begin{array}{l}\text { No peak } \\
\text { (type B) }\end{array}$ & $\begin{array}{c}\chi^{2} \\
\text { Trend }^{\star}\end{array}$ \\
\hline \multicolumn{6}{|l|}{ Sex: } \\
\hline Girls & $63 \cdot 1(275)$ & $17 \cdot 0(74)$ & $12 \cdot 4(54)$ & $7 \cdot 6(33)$ & \\
\hline Boys & $62 \cdot 2(271)$ & $17 \cdot 2(75)$ & $9 \cdot 4(41)$ & $11 \cdot 2(49)$ & 0.60 \\
\hline \multicolumn{6}{|c|}{ Social class of head of household: } \\
\hline I & $63.9(62)$ & $16 \cdot 5(16)$ & $12 \cdot 4(12)$ & $7 \cdot 2(7)$ & . \\
\hline II & $63 \cdot 9(145)$ & $14 \cdot 5(33)$ & $14 \cdot 5(33)$ & $7 \cdot 1(16)$ & \\
\hline IIIN & $62 \cdot 4(108)$ & $21 \cdot 4(37)$ & $5 \cdot 2(9)$ & $11 \cdot 0(19)$ & 0.00 \\
\hline IIIM & $65 \cdot 2(118)$ & $17 \cdot 7(32)$ & $6 \cdot 6(12)$ & $10 \cdot 5(19)$ & \\
\hline IV/V & $62 \cdot 9(66)$ & $14 \cdot 3(15)$ & $17 \cdot 1(18)$ & $5 \cdot 7(6)$ & \\
\hline Unknown $\dagger$ & $52 \cdot 8(47)$ & $18 \cdot 0(16)$ & $12 \cdot 4(11)$ & $16.9(15)$ & \\
\hline \multicolumn{6}{|c|}{ Tenure of housing: } \\
\hline Owned & $64 \cdot 6(396)$ & $16 \cdot 3(100)$ & $10 \cdot 6(65)$ & $8 \cdot 5(52)$ & \\
\hline Rented & $57 \cdot 8(147)$ & $18 \cdot 5(47)$ & $11 \cdot 8(30)$ & $11 \cdot 8(30)$ & $3 \cdot 80$ \\
\hline \multicolumn{6}{|c|}{ No of smokers in household: } \\
\hline 0 & $63.9(292)$ & $17 \cdot 3(79)$ & $10 \cdot 7(49)$ & $8 \cdot 1(37)$ & \\
\hline 1 & $63 \cdot 3(169)$ & $16 \cdot 5(44)$ & $10 \cdot 9(29)$ & $9 \cdot 4(25)$ & $3.97 \ddagger$ \\
\hline$\geqslant 2$ & $56.4(79)$ & $17 \cdot 1(24)$ & $12 \cdot 1(17)$ & $14 \cdot 3(20)$ & \\
\hline \multicolumn{6}{|c|}{ Fifths of salivary cotinine $(\mathrm{nmol} / \mathrm{l})$ : } \\
\hline$<0.57$ & $64 \cdot 8(70)$ & $15 \cdot 7(17)$ & $12 \cdot 0(13)$ & $7 \cdot 4(8)$ & \\
\hline $0 \cdot 57-$ & $72 \cdot 6(130)$ & $13 \cdot 4(24)$ & $8.9(16)$ & $5.0(9)$ & \\
\hline $2 \cdot 27-$ & $65 \cdot 4(104)$ & $20 \cdot 8(33)$ & $5 \cdot 7(9)$ & $8 \cdot 2(13)$ & $7 \cdot 015$ \\
\hline $7 \cdot 38-$ & $61.0(89)$ & $17 \cdot 8(26)$ & $6.9(10)$ & $14 \cdot 4(21)$ & \\
\hline$>19.9$ & $58 \cdot 3(84)$ & $16.7(24)$ & $12 \cdot 5(18)$ & $12 \cdot 5(18)$ & \\
\hline
\end{tabular}
$\star \mathrm{df}=1$.
excluded from the test for linear trend.

$\neq \mathrm{p}<0.05$. $\quad \int \mathrm{p}<0 \cdot 01$.

TABLE III - Distribution of salivary cotinine concentrations according to number of smokers in household

Salivary cotinine $(\mathrm{nmol} / \mathrm{l})$

\begin{tabular}{|c|c|c|c|c|c|}
\hline $\begin{array}{l}\text { No of smokers in } \\
\text { household }\end{array}$ & Minimum & First quartile & Median & $\begin{array}{c}\text { Third } \\
\text { quartile }\end{array}$ & Maximum \\
\hline $0(n=405)$ & ND & ND & $1 \cdot 1$ & $2 \cdot 3$ & 36.9 \\
\hline $1(n=241)$ & ND & $4 \cdot 5$ & $10 \cdot 2$ & $22 \cdot 7$ & $205 \cdot 0$ \\
\hline$\geqslant 2(n=124)$ & $2 \cdot 3$ & 12.5 & $25 \cdot 0$ & 37.5 & $97 \cdot 1$ \\
\hline Total $(n=770)$ & ND & 0.6 & $4 \cdot 0$ & $16 \cdot 5$ & $205 \cdot 0$ \\
\hline
\end{tabular}

$\mathrm{ND}=$ None detected $(<0.57 \mathrm{nmol} / \mathrm{l})$. children of unknown social class. There was a significant trend towards abnormal tympanograms in the children whose parents were smokers, and the prevalence of effusion increased with the number of smokers in the household $\left(\chi^{2}\right.$ for trend in proportions $=4 \cdot 15, \mathrm{df}=1, \mathrm{p}<0.05)$. There was a similar trend, which was of borderline significance $(p=0.051)$, associated with rented housing.

The results of the salivary cotinine assay were available for 770 children (405 from non-smoking households, 241 from households with one smoker, and 124 from households with two or more smokers). Table III shows the distributions of salivary cotinine concentrations in these three groups. A total of 109 (27\%) children from households with no smokers had concentrations below the limit of the assay $(0.57 \mathrm{nmol} / \mathrm{l})$, whereas only one child from a household with one or more smokers had no detectable salivary cotinine. Six children, five of them from households with only one smoker, had concentrations $>82 \mathrm{nmol} / \mathrm{l}$, a suggested cut off point to distinguish between smoking and non-smoking adults and adolescents. ${ }^{1820}$ These values were $93 \cdot 1,97 \cdot 1,106 \cdot 2$, $119 \cdot 3,144 \cdot 8$, and $205 \cdot 0 \mathrm{nmol} / 1$.

Table IV shows the relation between cotinine concentrations, sex of the children, and housing tenure within groups with similar numbers of smokers in the home.

TABLE IV-Geometric mean salivary cotinine concentrations ${ }^{\star}$ (nmol/l) in 770 children aged 7 according to sex of child, housing tenure, and number of smokers in household. Numbers of children are given in parentheses

\begin{tabular}{|c|c|c|c|c|}
\hline \multirow{3}{*}{$\begin{array}{c}\text { No of } \\
\text { smokers in } \\
\text { household }\end{array}$} & \multicolumn{4}{|c|}{ Tenure of housing } \\
\hline & \multicolumn{2}{|c|}{ Owned } & \multicolumn{2}{|c|}{ Rented } \\
\hline & Boys & Girls & Boys & Girls \\
\hline 0 & $0.85(176)$ & $1.02(161)$ & $3.01(35)$ & $8.63(33)$ \\
\hline 1 & $5.62(67)$ & $0.53(74)$ & $17 \cdot 04(53)$ & $25.95(47)$ \\
\hline$\geqslant 2$ & $15 \cdot 61(28)$ & $17 \cdot 04(33)$ & $21.47(30)$ & $34 \cdot 36(33)$ \\
\hline
\end{tabular}

* Undetectable concentrations were recorded as $0.28 \mathrm{nmol} / \mathrm{l}$.

In view of the skewed nature of the distributions for cotinine concentrations the table gives geometric mean values. For logarithmic transformation undetectable concentrations were treated as $0.28 \mathrm{nmol} / \mathrm{l}$. Female sex and rented housing were independently and consistently associated with higher cotinine concentrations given the same number of smokers in the household. These effects were apparent even in non-smoking households, and the difference with sex was particularly pronounced among children from rented homes.

Satisfactory tympanograms were obtained for 736 of the 770 children for whom we had data on salivary cotinine concentrations. When cotinine concentrations were grouped in fifths of the distribution there was a highly significant trend towards more abnormal tympanograms in the children with higher concentrations (table II). In view of the associations between cotinine concentrations and sex of the child and housing tenure and the modest effect of these factors on the prevalence of middle ear effusion the relation between salivary cotinine concentrations and abnormal tympanograms was analysed further by multiple logistic regression. Presence or absence of effusion (type B tympanogram) was treated as a dichotomous outcome variable. To investigate the form of the dose-response relation in more detail the data on cotinine concentrations were fitted as a continuous explanatory variable. The logarithm of the cotinine concentration was found to give the best fit, its relation to the prevalence of type B tympanograms being close to linear on a logarithmic scale $\left(\chi^{2}\right.$ for inclusion of quadratic term $=0.0000, \mathrm{df}=$ $1)$.

In single factor models the odds ratio for female sex was 1.53 (95\% confidence interval 0.92 to 1.98$)$, and 
for rented housing it was $1.43(0.84$ to 2.42$)$. The effect of the logarithm of the cotinine concentration in a single factor model was significant $\left(\chi^{2}=6 \cdot 60, \mathrm{df}=1\right.$, $\mathrm{p}<0.02$ ), and the odds ratio for a doubling of salivary cotinine concentration was $1 \cdot 14(1.03$ to $1 \cdot 27)$. In a joint model including all three factors the effects of sex and logarithm of the cotinine concentration changed little, but there was an appreciable reduction in the odds ratio for children living in rented housing, suggesting that passive exposure to smoke accounted for much of the effect of rented housing in the single factor models. The adjusted odds ratios were 1.46 $(0.87$ to 2.44$)$ for female sex, $1.03(0.55$ to 1.91$)$ for rented housing, and $1.13(1.00$ to 1.28$)$ for a doubling of salivary cotinine concentration. The effect of the logarithm of the cotinine concentration remained significant in the joint model $\left(\chi^{2}=4 \cdot 14, \mathrm{df}=1, \mathrm{p}<0.05\right)$. Further adjustment for parental social class, number of people living in a room, gas cooking, and the presence of damp walls in the home made no substantial difference to the coefficient for the logarithm of the cotinine concentration.

The linear relation between the logarithm of the cotinine concentration and the prevalence of middle ear effusion on a logit scale implied that the prevalence odds were proportional to a power of the cotinine concentration, the power exponent being the coefficient (logarithm of the odds ratio) for the logarithm (base e) of the cotinine concentration in the logistic model. The data suggested that the odds ratios for type B tympanograms after adjustment for sex and housing tenure relative to children with undetectable cotinine concentrations would be approximately 1.7 at 5.7 $\mathrm{nmol} / \mathrm{l}(1 \mathrm{ng} / \mathrm{ml})$ and $2 \cdot 3$ at $28 \cdot 4 \mathrm{nmol} / 1(5 \mathrm{ng} / \mathrm{ml})$. Thus even low levels of passive exposure to smoke may have substantial effects on the prevalence of middle ear effusion. The model predicted that in a population of the same distributions of age, sex, and tenure in which all children had undetectable cotinine concentrations the prevalence of type B tympanograms would be approximately $5 \cdot 8 \%$. As the observed prevalence was $9.4 \%$ at least one third of the cases of middle ear effusion in this age group may have been attributable to passive smoking.

\section{Discussion}

We believe that this is the first study to report biochemical data on passive exposure to smoke in primary school children. The age group chosen was young enough to exclude regular active smoking, but some of the higher concentrations of salivary cotinine observed were greater than could reasonably have been attributed to passive exposure. These high concentrations may indicate experimentation with cigarettes, even at this early age. None of the six children with cotinine concentrations above $82 \mathrm{nmol} / 1$, however, had middle ear effusion (five had normal (type A) tympanograms), so their inclusion in the analysis will have tended to diminish any effects attributed to passive exposure to smoke rather than to generate a spurious effect.

As expected, cotinine concentrations were related to the number of smokers in the household, but equally striking was the variation with sex of the children and housing tenure within groups with the same numbers of smokers. Even among the children from nonsmoking households cotinine concentrations were higher in those living in rented accommodation. This suggests that considerable exposure to smoke occurs outside the home, which is strongly related to social factors. When tenure and number of smokers were controlled for girls had higher salivary cotinine concentrations than boys. This may reflect differences in cotinine metabolism or in activity patterns, boys being perhaps more likely to play outdoors or away from adults who smoke. No difference with sex has been found in older children. ${ }^{19}$

The prevalence of abnormalities on tympanometry in this population of 7 year old children is consistent with previous reports. ${ }^{28} 29$ Tympanometry was performed only once, and many of the abnormalities detected, including middle ear effusion, tend to resolve spontaneously. ${ }^{29}$ This population survey probably included only a few cases of persistent disease in which an operation would be indicated. The findings are therefore complementary to, rather than directly comparable with, case-control studies of children admitted to hospital. ${ }^{3.5}$ They do, however, relate to an age group close to the peak age for admission for an operation for middle ear effusion.

Our results show a significant relation between salivary cotinine concentrations and disease of the middle ear, whether a range of abnormal tympanograms, or tympanograms with and without a definable peak (taken to indicate effusion) are considered. These associations were probably not due to bias because the measurements were objective and the laboratory analysts were blind to the tympanometric findings. Adjustment of the crude estimates of the effect of sex and housing tenure on cotinine concentrations indicated some confounding by these factors, but confounding by socioenvironmental factors probably did not persist in the final model. The coefficient for housing tenure in the joint model was small, and further adjustment for social class and a range of more specific housing characteristics made little difference to the results.

Salivary cotinine concentrations relate only to passive exposure to smoke in the previous two or three days, but Jarvis et al reported that over one year concentrations in non-smoking adolescent girls was reasonably stable. ${ }^{30}$ Nevertheless, variation in exposure from week. to week limits the reliability of a single measurement, and the true association between passive smoking and middle ear effusion is therefore underestimated in our data. ${ }^{31}$

The relation between passive exposure to smoke and middle ear effusion in the present study is more likely to be causal than due to chance, bias, or confounding factors. The common mechanism in the development of serous otitis media is considered to be loss of patency of the eustachian tube, to which anatomical factors, impaired mucociliary function, and upper respiratory infection or allergy may contribute. ${ }^{32}$ Passive smoking may increase the risk of blockage of the eustachian tube in three ways: by directly impairing mucociliary function; by causing congestion of the soft tissues of the nasopharynx; or by predisposing people to upper respiratory infection. Because this was a study of the prevalence of middle ear effusion we cannot draw conclusions about whether exposure to smoke influences the incidence or the persistence of the disease.

Concern has been expressed recently that the documented risks of passive smoking have not included middle ear effusion. ${ }^{33}$ In view of the important burden on the health service imposed by this disease ${ }^{1}$ and suspicions of its long term effects on linguistic and cognitive development ${ }^{34}$ middle ear effusion in children should be regarded as one of the more important hazards attributable to environmental tobacco smoke.

Analysis of saliva specimens was supported by grants from the Wellcome Trust and the Medical Research Council. The fieldwork was supported by a grant from the Asthma Research Council.

1 Black N. Surgery for glue ear-a modern epidemic? Lancet 1984;i:835-7. 2 Black N. Causes of glue ear. An historical review of theories and evidence. f Laryngol Otol 1985;99:953-66. 
3 Kraemer MJ, Richardson MA, Weiss NS, et al. Risk factors for persisten middle ear effusions: otitis media, catarrh, cigarette smoke exposure and atopy. FAMA 1983;249: 1022-5.

4 Black N. The aetiology of glue ear-a case-control study. Int $\mathcal{f}$ Pediat Otorhinolaryngol 1985;9:121-33.

Hinton AE, Buckley G. Parental smoking and middle ear effusions in children. f Laryngol Otol 1988;102:992-6.

6 Black N. "Health culture" of families as an influence on the use of surgery for glue ear: a case-control study. Int $\mathcal{f}$ Epidemiol 1985;14:594-9.

Black N. Geographical variations in the use of surgery for glue ear. $7 R$ Soc Med 1985:78:641-8.

8 Iversen $M$, Birch L, Lundqvist GR, Elbrond O. Middle ear effusion and the indoor environment. Arch Environ Health 1985;40:74-9.

9 Vintner B, Elbrond O, Brahe Pedersen C. A population study of otitis media in childhood. Acta Otolaryngol [Suppl] (Stockh) 1979;360:121-3.

10 van Cauwenberge $P B$. Relevant and irrelevant predisposing factors in secretory otitis media. Acta Otolaryngol [Suppl](Stockh) 1984;414:147-53.

11 Birch L, Elbrond $O$. A prospective epidemiological study of secretory otitis media in young children related to the indoor environment. $O R L \mathcal{J}$ Otorhinolaryngol Relat Spec 1987;49:253-8.

12 Zielhus GA, Rach GH, van den Broek P. Predisposing factors for otitis media with effusion in young children. Adv Otorhinolaryngol 1988;40:65-9.

13 Brooks DN. An objective method of detecting fluid in the middle ear International Audiology 1968;7:280-6.

14 Fria TJ, Cantekin EI, Probst G. Validation of an automatic otoadmittance middle ear analyzer. Ann Otol Rhinol Laryngol 1980;89:253-6.

15 Fiellau-Nikolajsen M. Tympanometry and secretory otitis media. Acto Otolaryngol [Suppl] (Stockh) 1983;394:1-73.

16 Feyerabend C, Bryant AE, Jarvis MJ, Russell MAH. Determination of cotinine in biological fluids of non-smokers by packed column gas-liquid colno in

17 Jarvis $M$, Tunstall-Pedoe H, Feyerabend C, Vesey C, Saloojee Y. Biochemical markers of smoke absorption and self-reported exposure to passive smoking. I Epidemiol Community Health 1984;38:335-9.

18 Jarvis MJ, Tunstall-Pedoe H, Feyerabend C, Vesey C, Saloojee Y. Comparison of test used to distinguish smokers from nonsmokers. Am f Public Healt

19 Jarvis MJ, Russell MAH, Feyerabend C, et al. Passive exposure to tobacco smoke: saliva cotinine concentrations in a representative population sample of non-smoking schoolchildren. Br Med $\mathcal{F}$ 1985;291:927-9

20 McNeill AD, Jarvis MJ, West R, Russell MAH, Bryant A. Saliva cotinine as an indicator of cigarette smoking in adolescents. Br $\mathcal{F}$ Addict 1987;82:1355-60.

21 Strachan DP. Damp housing and childhood asthma: validation of symptom reporting. Br Med f 1988;297:1223-6.

22 Office of Population Censuses and Surveys. Classification of occupations and coding index. London: HMSO, 1980.

23 Jerger J. Clinical experience with impedance audiometry. Archives of Otolaryngology 1970;92:311-24.

24 SAS Institute. SAS user's guide: basics. Version 5. Cary, North Carolina: SAS Institute, 1985 .

25 SAS Institute. SAS user's guide: statistics. Version 5. Cary, North Carolina: SAS Institute, 1985.

26 Baker RJ, Nelder JA. The GLIM system manual (release 3). Oxford:Numerical Algorithms Group, 1978 .

27 Mantel N. Chi-square tests on one degree of freedom: extensions of the Mantel-Haenszel procedure. Journal of the American Statistical Association 1963;58:690-700

28 Portoian-Shuhaiber S, Cullinan TR. Middle ear disease assessed by impedance in primary school children in south London. Lancet $1984 ; \mathrm{i}: 1111-2$.

29 Lous J, Fiellau-Nikolajsen M. Epidemiology of middle ear effusion and tuba dysfunction. A one-year prospective study comprising monthly tympanometry in 387 non-selected 7-year-old children. Int f Pediatr Otorhinolaryngol 1981;3:303-17.

30 Jarvis $M J$, McNeill AD, Russell MAH, West RJ, Bryant A, Feyerabend C. Passive smoking in adolescents: one-year stability of exposure in the home. Lancet 1987;i:1324-5.

31 Cochran WG. Errors of measurement in statistics. Technometrics 1968;10:637 66.

32 Maw AR. Otitis media with effusion (glue ear). In: Kerr AG, Groves J, Evan NG, eds. Scott-Brown's otolaryngology. Sth ed. Vol 6. London: Butterworths, 1987:159-76.

33 Etzel RA. Smoke and ear effusions. Pediatrics 1987;79:309-10.

34 Maran AGD, Wilson JA. Glue ear and speech development. Br Med $\mathcal{J}$ $1986 ; 293: 713-4$

(Accepted 5 April 1989)

\title{
Relation between mortality and treated blood pressure in elderly patients with hypertension: report of the European Working Party on High Blood Pressure in the Elderly
}

\author{
J Staessen, C Bulpitt, D Clement, P De Leeuw, R Fagard, A Fletcher, F Forette, G Leonetti, \\ A Nissinen, K O'Malley, J Tuomilehto, J Webster, B O Williams
}

\section{Abstract}

Objective-To investigate the relation between mortality and treated systolic and diastolic blood pressures.

Design-Randomised double blind placebo controlled trial. Mortality in the two treatment groups was examined in thirds of treated systolic and diastolic blood pressures.

Patients-339 And 352 patients allocated to placebo and active treatment, respectively. The groups were similar at randomisation in sex ratio ( $70 \%$ women), mean age $(71.5$ years), blood pressure $(182 / 101 \mathrm{~mm} \mathrm{Hg})$, and proportion of patients with cardiovascular complications (35\%).

Measurements and main results-In the placebo group total mortality rose with increasing systolic pressure whereas it had a $U$ shaped relation with diastolic pressure, the total lowest mortality being in patients in the middle third of the distribution of diastolic pressure. In the group given active treatment total mortality showed a $U$ shaped relation with systolic pressure and an inverse association with treated diastolic pressure. In both groups cardiovascular and non-cardiovascular mortality followed the same trends as total mortality. The increased mortality in the lowest thirds of pressure was not associated with an increased proportion of patients with cardiovascular complications at randomisation or with a fall in diastolic pressure exceeding the median fall in pressure in each group. In contrast, patients in the lowest thirds of pressure showed greater decreases in body weight and haemoglobin concentration than those in the middle and upper thirds of pressure.
Conclusions - In patients taking active treatment total mortality was increased in the lowest thirds of treated systolic and diastolic blood pressures. This increased mortality is not necessarily explained by an exaggerated reduction in pressure induced by drugs as for diastolic pressure a $U$ shaped relation also existed during treatment with placebo. In addition, patients in the lowest thirds of systolic and diastolic pressures were characterised by decreases in body weight and haemoglobin concentration, and the patients in the lowest thirds of diastolic pressure taking active treatment also by an increased non-cardiovascular mortality, suggesting some deterioration of general health.

\section{Introduction}

Several large studies of hypertension have recently been reviewed. ${ }^{12}$ The observation in these studies of a $J$ shaped relation between the risk of myocardial infarction and treated blood pressure ${ }^{3-9}$ has led to the suggestion that a reduction of pressure induced by drugs might cause as well as prevent myocardial ischaemia. ${ }^{1011}$ None of the studies was placebo controlled, and other large hypertension-mortality intervention trials have either not confirmed ${ }^{12-14}$ or not reported ${ }^{15}{ }^{16}$ this $\mathrm{J}$ shaped relation. In the international prospective primary prevention study in hypertension all patients received active drugs but patients with overt ischaemic heart disease were excluded ${ }^{14}$; there was no evidence for a J curve. In contrast, Coope and Warrender found that total mortality and deaths from myocardial infarction showed a J shaped relation with the diastolic pressure attained in elderly patients with

Hospital Gasthuisberg, 